\title{
Island
}

\section{Samantha Trayhurn}

\author{
Western Sydney University
}

So that the monotonous fall of the waves on the beach, which for the most part beat a measured and soothing tattoo to her thoughts seemed consolingly to repeat over and over again...

- To the Lighthouse, Virginia Woolf

My hair draggles

in drenched coils

I could be Medusa

out for a stroll

- The Monkey's Mask, Dorothy Porter

Trigger warning: This story contains depictions of violence and sexual assault. 


\section{Prelude}

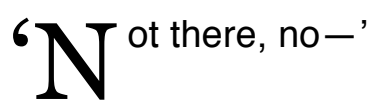

I push but there's no push in me-my heavy limbs fall onto the sand. Conches wedge into my spine like new vertebrae. 'Calcify,' the crabs whisper. 'Become crustacean! Scurry into the ocean.' Or, 'Sew legs shut with the discarded nets. Become a mermaid with nothing down there!'

Bass thrums from behind the trees as the last notes of the Jungle Disco fizzle out.

'No, not there-'

Two men are talking, laughing, their hot breathy accents are inside my ears, their tongues heavy as soaked serviettes.

'What the fuck?' one of them says.

He's felt my cock now and he's pulling me, pushing me, laying me down, twisting me. My fingers grab the ground to stop the spinning but it's slipping through-fistfuls of sand. Four hands are holding me and I'm pushing, but there's no push left. Knuckles connect with my jaw.

'Freak!' the other man spits.

An angel in her white dress stops down the beach. I see her fuzzy glow, watching. Not a saviour though, not that kind of angel. She turns and goes. The glint of an upturned beer can catches the first spark of sun; the fizzy contents poured over me. The men go too, leaving behind their wetness, a lingering essence of yeast.

A squawk. I jerk my head to see gulls hovering. With open beaks they break the dawn, their hollow eyes on me. I smooth cotton over the shameful parts. Tucked up again, better. Skin hot now; I can smell something acrid, like feathers burning.

In the distance some dogs bark; I lick blood from my lips. The copper tastes like last night's beer bottles with no ring seals in the caps to mask the rust.

Inside my head feels soft now, cushioned for sleeping. Most of me is already numb, but my nerves feel the scamper of crabs retreating into burrows like the straggling revellers finding their beds. A low buzzing-flies mingling with the first sounds of fishing boats. 
Sand congeals to paste beneath me and blood trickles to sea with the certainty of innards flung from a caught tuna. The tide brings and takes. If I could, I would tell the tide everything, but my eyes are with the birds already, and these lips will be bones soon enough.

I sink into the island until I feel nothing but the vibrato of waves breaking along the beach, like the hearts of hopeful girls. 


\section{Saturday}


There's nothing like the feeling of sweat on my skin before 6am. It's good to be back! I suck in the smell of a Siargao Island morning. Pan de Coco on the grill, yesterday's fish guts rotting by the roadside, salt drying out every surface. The moisture in the air is so thick, I can almost open my mouth and drink it.

Last summer I spent a month riding these waves, exploring roads and valleys, drinking warm beer and strong rums. Mum wasn't too impressed when I told her l'd deferred uni to come back, but Mum'll get over it like she always does.

'Jill,' she said, 'when are you going to grow up?'

'Never,' I smiled, blowing her a kiss as I ran to the departure gate, my name blaring over the airport speakers.

When the email with the job offer came from Vera, one half of the Swedish couple who own Isla Blue, I had to take it. Tend bar, guide the horse tours, assist the guests. Sounded easy, almost too good to be true.

Growing up in the hinterland of northern New South Wales, I've been around horses my whole life, and I've got heaps of hospitality experience. At home, rich businessmen'll talk your ear off about stocks, but they only tip the girls with good cleavage. Here at the bar, I'll meet people from all over the world; at the very least the conversation'll be better.

To be honest, I don't really know how it came about. I can barely remember what was said on those late nights at the Isla. Drunk on the potent slush of mango, Tanduay rum, and cordial taken in shots. I do remember Eddie's hand on my waist, slipping out from his station behind the bar to refill my glass; Vera's hair to her knees, gliding from person to person with ballerina poise; Oscar's Euro tan, his sharp lips twisting to a smile with movie star charm. I must have made an alright impression.

Plane pushing, nose to clouds, I watched my old life get smaller, inching closer to a new one with the map on the back of the seat.

Yesterday afternoon, after twenty-two hours of travel, I landed at Sayak Airport with a head full of plane air and snippets from some shitty Hollywood blockbuster playing on repeat. Dehydrated and stinking of the cheap free wine they'd served on the flight, I wished I had that can of deodorant they confiscated at the security checkpoint in Manila.

Vera waited in the bright-lit baggage claim shed, waving a cupped hand in my direction; she glowed as if I was looking at her through a sheet of cellophane. Hugging me tightly, she held on long enough to make me self-conscious of my smell, and chatted breathlessly all the way across the carpark - a young mum who hadn't spoken to another adult in a while. 
In the banged up van with the resort name printed down the side in tacky cursive, she veered around deep potholes. Talking, eyes barely on the road, swerving just in time to miss a barechested, bare-footed surfer on motorbike heading home for the day, surfboard propped in his side rack like a lame bird holding out a wing. I gave him a sorry look and wave, held on to the door so tight my knuckles went white.

Once at the Isla, I dumped my bags in the caretaker bungalow that'd be my new home. I paused just long enough to take in the bare wood floors, the bamboo walls, the thin gauze curtains. Nicer than my old room in the share house back in Brisbane, its carpet stained with a family tree of all the dead beats who'd live there before me.

'Come say hi to Eddie and the children,' Vera said, shuffling me out to the bar for a welcome drink.

'I'm knackered,' I yawned. 'Just one.'

On a hammock hung between two palms, the maid pushed the children like they were on a playground swing. Elin and Ivar, naked as gumnut babies, sprung towards me, their tanned limbs wrapping my legs. Bright blonde bowls of hair on each of their heads made them look like twins despite the two-year age difference.

Eddie greeted me with a strong one-armed hug and slid me a pina colada made with fresh pineapple, and coconuts straight from the trees overhead.

'Welcome back,' he said.

Dark eyes, faded tattoos up his arms to his neckline; he cracked a half smile, dropping his hard exterior for a minute.

'My favourite drink,' I said, taking a long sip, knowing he'd remembered.

Most resorts on Siargao Island are owned by wealthy FIFO Euros who arrived in the 90s when it was still undeveloped blocks of coconut palms. In the off season, businesses are left in the hands of a few trusted locals and a revolving door of bright young faces, like me, willing to work for board and a little spending money on the side. Oscar has already returned home to his summer job. Next week Vera'll join with the children. Then, it'll just be Eddie and I in charge of the bar, five bungalows, a maid, four horses and a stablehand.

For now, the day is yet to begin and my sneakers pound the familiar surface of the one concrete road out of General Luna. For the average visitor, days here are broken up into the highs and lows of the tides; the hours between filled with drinking, eating, smoking, sleeping, shagging. Nothing ever happens on time, but no one cares. As far as the locals are concerned, clocks are for cities with high-rises and traffic fumes. Island time runs slow and unreliable on the vapors of sweat and the ocean, which is fine by me. 
Last time, I showed up with my board and backpack planning to stay a week; I didn't leave until my thirty-day visa ran out.

Morning light on Tourism Road is grey like sea-wash before the sun has properly risen, soaking through the spongy green, lining the concrete in a damp haze. I run past the resorts and restaurants, alongside the local houses, some just piles of driftwood propped together with sheets of corrugated iron and tarps for roofs. Children run alongside me in the local game, driving their knees up to their chests, mocking me with glee.

The island isn't a place where the locals run for enjoyment-for most life is pretty tough - so an androgynous western girl jogging for fitness is funny to most and annoying to some. I smile at the gruff men working on a motorcycle all the same. Unkind eyes take in my tattoos, my flat chest, and my short hair; at home those eyes might be followed up with an insult spat like 'dyke' or 'bitch', but here judgment is more reserved.

Rounding the bend, I trace the familiar route, through the field of coco palms with fighting cocks shackled to stakes, down the sandy path towards the skeleton of the old wooden jetty, its gnarled and broken bones now shadowed by the fresh concrete replacement that welcomes the tour boats each day.

Dogs bark as I run through the thick grass separating the expat houses on the eastern end of the beach from the neighboring settlements. Large fences fringed with shards of broken glass line the properties-primitive island security systems for keeping intruders out. To me, the island always felt safe enough, but you hear stories. A backpacker's room broken into, passports and laptops stolen. A nineteen-year-old French girl held at knifepoint walking home alone from the Jungle Disco, saved only by a passing jeepney.

I'm only short, but I'm broad and fit; men don't usually give me trouble and l've certainly never had any here. Light catches on the multi-coloured shards cemented into the fences edge. Hard to tell whether the worry is justified or if it's just a mosaic of fear and paranoia.

To my left, the beach is thatched with boat ropes from vessels marooned like suffocating fish, waiting for the currents to buoy them or for strong arms to push them out. I skip down from the small ledge into the hard sand. Eyes ahead, I see the glisten of children washing in the sea, darkest where the seaweed grows, lighter in the shallows, lightest still in the deeper pools. Gulls squawk overhead. I look down, jolted as my foot kicks something solid but not hard.

Heart stop. Blood hot. Gargled sound from my throat I don't recognise as mine.

Skin.

White skin.

Dead skin. 


\section{Exposed skin.}

A girl's skin.

No.

Her blonde hair is splayed like the fans of seaweed scattered along the sand. I scan her body, her clothes; the deep bruises on her skin. Her head is tilted so I can't see her eyes. I don't want to see her eyes. What has she seen?

Her body is twisted. Her dress unbuttoned-wet-her breasts melting away from each other, sliding across her chest, nipples twisting towards the sun like flowers. Flecks of orange and brown dried vomit pool under her, around her, on her.

I can smell it then, sex, like clag glue. I choke on the acid at the back of my throat.

Where the children were playing a few minutes ago, there's no one now. Probably inside getting ready for school; no thoughts of dead girls anywhere in their happy little heads.

Shit.

I run towards the settlement where their mothers dress them. Try and explain in simple words I hope they'll know.

'Help ... please ... police.'

Two women even shorter than me take my hands, guide me towards a piece of driftwood made into a garden bench, and push me to sit. They can't understand what I'm saying but they rub my back like mothers do. Children stand and stare as I gasp. Drowning in air. I close my eyes but she's still there. 
Ensam går jag här och vankar, Söker efter vännen min.

I walk alone and wander here.

Singing an old folk song my mother used to sing me when I couldn't sleep, I close the front door gently. Hum hum tippy toe tippy toe, up the stairs, quiet now, careful not to wake the children.

In their room, the two little ones sleep in circles of light. Dawn unshadows their blonde hairalmost white-contrasted against their tanned skin like two dolls.

My Elin.

My Ivar.

I sit in the armchair in the corner, looking out over the flat sea to the waves breaking way out on the horizon. Surfers paddle out the harrowing distance to the cemetery; a break so named because it's parallel to the town burial site. No one has died out there yet. Not that I know of.

Death is a funny thing. One moment we're alive, the next we aren't. Sometimes when the children are sleeping, I can't be sure, so I hold my hand just close enough to feel the wisps of their breath. Tsp tsp tsp through snotty nostrils. Today, they are alive, their ribs rise and fall, fragile as birds. Tomorrow, who knows? I will check again.

Since Oscar left, I'm exhausted, floating through these scorching hours, evaporating. The children's energy wears me thin. When Oscar is around he runs with them, throws Ivar into the air, swings Elin by her arms in circles like a helicopter, making the chop chop chop sounds. I can barely keep up with them. They pull me by the hand on the beach, but I feel like an anchor being dragged.

On the phone last week my brother told me he thought I might need anti-depressants. I laughed. There's no psychologists in town, just a few pharmacists who prescribe Amoxicillin for just about every ailment, and the hospital all the way in Dapa. I think I'm just fed up. Getting anything done here is nearly impossible, especially as a woman.

When I picked Jill up from the airport I could barely contain my excitement at having a fresh face around. A sweet pixie thing. A bit rough around the edges, but that's not so bad. The prettier they are, the more trouble, usually.

Each off-season we find someone to keep an eye on things, and it's always worked out. A British couple put a hole in the wall fighting, the American yoga instructor burnt holes in the sheets with her cigarettes, the Spaniard smashed a window when he lost his keys, but nothing a few pesos can't fix. It's not the Hilton; we're barely booked in the quiet months. 
Next week, from the airplane, I will point to the island becoming a speck out the circular window as Ivar's eyes widen.

'Bye-bye,' Elin will say replicating the sway of the palm trees waving us off with her little hand.

I won't miss it. Not this time. We've been coming and going for over a decade, but, now that the children are two and four, I long for my real home. Home. What has that word become? In the streets of Stockholm, I'll wear a coat and leather boots. I'll pull my scarf tight around my throat and put rouge on my already flush cheeks. I will pull my hat down over my ears as the morning wind whips our backs.

My horses, though, I'll miss those beautiful Arab creatures! The first time I put my feet on the sand here I said to Oscar the only thing missing were horses to ride at sunset. No matter how old she is, a girl always dreams of horses.

'We will bring them,' he promised.

Then, last year, they arrived on a ferry from Cagayan de Oro. Women screamed when the handlers first galloped them down the road, clip clop, clip clop; I guess most of the locals had never seen a horse before. That first night, closing the gates on their stables, I kissed them all on the white diamonds in the centre of their heads and cried like when Father presented me my first pony, a yellow bow around her neck. Already, they are great for business.

Feet running across the wooden deck outside.

'Maam Vera?'

The children stir. Ivar starts to cry. Scooping him from his cot, I shush his shrieks, wipe the thick mucus from his nose with my hand. Swinging the door, I see Mary in her smock, looking away, not wanting to meet my eye.

'What...part...of...don’t...disturb...me...did...you...fail...to...understand?' I hiss.

'I'm sorry Maam, but the police-' she stammers. Ivar shrieks louder.

I walk out onto the balcony. Sputter sputter, the weathered van with PULIS stenciled on in thin watery paint cuts through the morning silence. The resort is empty tonight--no guests to wake with the noise. The two neighbourhood officers stand by the stables with Jill. Little more than children themselves, the three of them should be trudging home from an all nighter at the Jungle Disco, not huddled in my driveway at daybreak.

'They say that Maam Emma is dead, Maam-' Mary's voice cracks as she says the words, 'Maam Jill saw her, Maam-on the beach-' 
Ivar shrieks and shrieks.

'Mummy,' Elin shouts from her room upstairs.

My head is light, the air passes through the perforations between the words and sounds and thoughts. I'm wearing thin, almost translucent. Nothing quite makes sense. I'm tired. So tired. Hot already as the sun rises in the sky. Evaporating. Floating like lace. 
'Emma Kent...They reckon her name was Emma Kent...Australia, she was from Australia too...Perth, I think...'

'Nah, Mum, I'm not coming home...I know, but I found her...I can't leave...Besides, I don't want to.'

'Nah...I don't need any money... don't come! Please, can you just...'

'Yeah Mum, I know...I love you too...l'll talk to you soon...'

Still wet from the shower, I shiver in the wind. Mum will still be sitting by the phone back on the farm worrying herself sick. When I moved to Brisbane for uni, she was left on her own; now her only daughter is mixed up in some island murder scene. I have to remember to be nicer to her.

I walk to the edge of the stables and look at the horses, oblivious to the chaos, smug in their quiet way. Ever since I was a kid, l've always loved horses. The calming smell, the soft and bristly skin around their mouths as they nuzzle, their black eyes that go all the way to infinity. Dad used to say that horses were the best judges of character.

I reach my hand out towards the golden female. She sniffs me uncertainly and blows out a puff of air before letting me unknot her mane.

'Hello Maam.'

I jump at the voice behind me.

'Sorry I didn't mean to scare you,' says Joshua, the stablehand.

We met briefly yesterday but haven't said much to each other. Still too shaken for words, I nod as he approaches. About nineteen, I guess from looking at the spread of pimples on the underside of his chin and the moustache on his upper lip not quite grown in. Muscles press against his tight fitting singlet as if trying to breakout from his thin-hipped boy body.

'You like horses Maam?' he asks.

'Yeah,' I reply.

'Zeus...Calliope...Icarus...Hercules...,' he says pointing to each by its name.

'Yeah, beautiful,' I murmur, continuing to wrestle with the knots in Calliope's mane. She yanks her head away as my fingers catch and pull too hard.

'Emma... I mean Maam Emma, liked them too,' Joshua says, his voice trailing off. 
I look over at the mention of the girl's name. I can't be sure as he fills the feed troughs with water and grain, but I think there are tears in his eyes.

'Did you know her?' I ask.

He begins to answer but stops. Vera is coming towards us from her house. Backlit - ethereal in her white sundress. She raises her hand to her heart when she sees me and lifts the dress from the ground to run across the few metres of lawn. Bony arms, the smell of lavender, the softness of a woman. I think of Mum. I think of those ladies who helped me when I found her. I think of Emma Kent.

'My god,' Vera says, 'how are you?'

The whole day so far has been a fog; in my room I lay staring at the water-stained ceiling, the yellowed blotches distorting into the shape of the girl. Emma Kent. Emma Kent. Emma Kent. The smell didn't wash off. I want Vera's fragrant cleanliness.

'I'll be right,' I say.

At the bar Vera pours me a glass of wine from the tiny piccolo bottles they sell, the red chilled alongside the white. Blood, but not blood. Emma's blood was much brighter; like sap from the trees l'd hack at in our yard as a kid, or spilled nail varnish, the colour that airhostesses wear.

I drink the cool liquid down. Eddie polishes the glasses silently, shaking his head. He's lived on the island his whole life and always has something to say about the state of affairs. Today he's silent. I drink and Vera returns to the house to feed the children.

Directly in front of the resort, a smaller island juts out against the horizon. I watch the boats ferrying sunburnt bodies back against the setting sun. The outriggers cut across the still water, rippling out in broad strokes like the postcards they sell at the souvenir shop next door. How blissfully unaware they all must be. Just another day in paradise.

'Excuse me Maam,' Joshua says from behind me.

I turn and look at him standing awkwardly, dirt smeared over the torn legs of his jeans.'You want to ride tomorrow?'

'Sure,' I reply with a shrug.

'Ok,' he says. 'Good night, Maam.'

I watch him go back to the cubbyhole where he lives above the storage shed, a little triangle window overlooking the stables, not much bigger than a closet. Head hanging, he drags his feet through the grass as the sound of the boats draw closer, a churning groan that says the 
day is over and the night is just kicking off. Soon, the bar will buzz with tourists, so I take my station next to Eddie and flick through the cocktail list, ready to be distracted by the smell of coconut, the whir of the blender, the chatter of a dozen accents blending into one soothing hum. 


\section{Sunday}


Late last night the police chief arrived from the mainland, came to the bar to let me know they're doing everything they can to find Emma's killer and that her body will be returned to Perth in a couple of days.

'We can hold a memorial here,' Vera said, overhearing from across her glass of rosé, 'so the island can say goodbye.'

I wonder how an island says goodbye. What words and gestures an island might choose?

The bonfire vigil has been assigned to Eddie and I to organise. On the rickety XRM bike that I've been loaned as part of the job, I fang over to the hostel where Emma worked, hoping to get a photo for the flyer.

'Last door on the left,' Marcel, the French owner points, still half asleep.

'Are you sure I can go in?' I ask, thinking of all the cop shows I've seen - evidence, finger printing, DNA.

'Yeah, the police have already messed it up.' He shrugs.

The room is a squat little private with an ensuite that smells like wet dog. Clothes are strewn all over the floor next to the single bed; snapshots and postcards blu-tacked to the wall over a tiny pine desk. I look closely. Athletic, strong, tall. I pull a photo down of her smiling widely with a group of other girls, dressed to the nines before a night out.

On the desk a dozen different types of blush and eyeshadow, hairpins, some prescription pills. I pick up one of the silver blister packs absent-mindedly and read the back. Estradiol Valerate. My eyes return to the photo, searching for clues. I recognise the name of the hormones from conversations with one of my friends who's transitioning back home. I put the packet down, guilty, like I've just outed her without permission.

Next to a hairdryer I notice a small pile of hand written notes. I gather them up with the photo and head out, suddenly overwhelmed by the presence of this girl I never knew.

'Get what you need?' Marcel asks through a haze of cigarette smoke.

'Yep, cheers,' I give him a wave as I pass.

'See you tomorrow night.'

Sunday is church day. Each barangay has its own Catholic basilica, the country's Spanish roots showing through. White and blue washed walls - carvings of the Virgin Mary or Jesus on each steeple. Not like the churches at home, all brown brick and boring. 
Propped up out of the saddle, Calliope accelerates to a gallop as we pass by the back of the Church of Iglesia Ni Christo. The courtyard is full with residents, devout in their half-hearted way. For most, it's a gathering of family, a sharing of food and drink, a day off work. After church, the streets empty of men who rush to the cock fights, another religion with a different set of gory images and rituals.

Joshua digs his heels into lcarus' side and takes off in front of me, looking back--a challenge. I pull the reigns to navigate around the mess of boat ropes, avoiding the spikes of anchors and obstacles. Children in the church cheer and wave.

'Kabayo! Kabayo! Kabayo!'

'Yyeeeahhhh!' I shout in response.

Leaning forward the rush of air lifts me out of the saddle; I hold on with my thighs, feeling Calliope's muscles extend and contract. Her neck propels the force of her whole body down through her hooves - muffled blows dashing the sand.

Around the bend the beach opens up and stretches out towards a bluff kilometres in the distance. I sidle up beside Joshua.

'Okay, Maam?'

'Bloody great!' I shout, 'And don't call me Maam! Jill is okay!'

Heat rushes through my veins like the shot of Tanduay I took with Eddie last night at closing time. I've ridden horses my whole life, but not for a few years now, and never like thisuntethered.

Reaching the bluff, we slow to a trot and dismount, tying the horses to some nearby palms to graze on the long grass.

'Did Emma ride with you often?' I ask, trying to find out more about how he knew her.

'Yes,' Joshua says, 'she rode like you. Fearless,' he laughs.

There's a pause as if he's somewhere in his memory, sitting with her on this beach instead of me.

'She liked to ride Icarus though, not Calliope. She said he was the fastest.'

'What was she like?' I ask.

He thinks for a moment before speaking, 'She was nice,' he says, 'and different...' 
I wait for him to continue but he doesn't. He stands, brushes the sand from his jeans and walks over to the horses, adjusting the bridles.

'We should get back,' he says. 'Maam Vera has a lot of work for me today.'

I take the hint that the conversation's over and swing my leg over the saddle. 
Clip clop, clip clop, clip clop. My fingers sound like the hooves of my horses. The long dining table stretches the length of Grace's dining room-one of three in her gigantic home. Grace is notoriously the richest woman on the island: her six star, all inclusive, $\$ 2000$ per person, per night resort welcomes a slew of celebrities and A-listers so of course, she'd prefer the pop sensation staying in the honeymoon suite didn't get news of a dead body while sipping her morning mimosa.

'Horrible, of course,' says Grace, looking down the dining table, 'but we can't have it drawn out too long. Word is getting out, soon guests will leave. No-one wants to be confined to an island where a murderer is on the loose.'

A dozen heads of hotel and bar owners nod in agreement. When I close my eyes, my lids feel heavy like someone has placed stones on them, lithic and cold.

'We aren't saying it is murder,' Officer Cruz cuts in. 'At the moment, it all looks like a messy accident. Choked on vomit probably... tampered with though... sexually...'

His accent is slightly different than the people here-a hint of American from the upper class international schools on the mainland. Perfectly tailored navy suit, he carries himself tall and straight like a modern metropolis, never faltering as he speaks. The proprietors look down at their food.

'She was raped?' Grace says. 'Well that's just great. Imagine when the female tourists hear... and Vera, your new girl that found her must-'

'Not exactly a her,' Cruz cuts in. 'Emma Kent, was, well, Eric Kent, according to the passport ..'

Eyes widen, a tittering of voices along the table. Overhead the fan struggles, catching on each rotation like a boat motor clogged with seaweed. Thrup thrup thrup. I watch irregular shadows cast across the walls. Marcel, Emma's boss at the hostel, looks surprised, like he's just seen a horse for the first time.

'Have the parents been informed?' he asks.

'Yes,' Cruz confirms. 'They were shocked of course, but hadn't had contact for a while. Said that Eric retreated to Thailand to undergo surgeries and hormone treatments. The last one was scheduled in a couple of months. The work here was helping to pay the bill. They said he liked living somewhere where nobody knew. Arrangements for the body have been made.'

'None of this has to get out,' Marcel cuts in. 'It's just too much for such a small community. It won't be good for anybody.' 
'Well, of course, discretion is always a concern, especially for businesses,' Cruz picks up his glass and downs the last sip of expensive whisky.

Grace's expensive leather handbag is imprinted with fleurs-de-lis, the dots and swirls of the pattern twirl across the surface. Only a few more days, I think, as Grace puts her hand into the bag and pulls out an envelope fat with bills.

'Something from us, to assist with the investigation,' she says sliding the envelope towards Cruz. 'We all feel that it would be best to see the whole matter dealt with promptly. Local men aren't accustomed to foreign women, and it's such a shame when a thing like this happens. A clear message really must be sent. An arrest sets an example for visitors and the locals alike, shows them that nothing like this will happen again.'

Cruz picks up the envelope and puts it inside his jacket with a nod, taking a long sip of his beer. Conversation turns to basketball and the upcoming Manny Pacquiao fight. I tune out and pick at the coastlines of black dirt forming under my fingernails, dreaming of the sterile smell of a nail salon.

'Now, if we can all return outside,' Grace cuts in. 'I have a party to host.'

The swimming pool is iridescent like the blue volcano in Bali Oscar and I saw on our honeymoon-lights dance and glimmer while well-dressed guests teeter on the edge. I want to throw myself into serene lava. I want to throw myself into a volcano and have the skin melt right off my bones, dripping like honey through the centre of earth and sprouting as a seedling on the other side. Home.

Ting ting ting, champagne glasses clink somewhere behind me. I think of the children back at the resort with Mary, their wet little faces propped in front of the computer screen watching a movie, scooping ice cream from bowls with steady clinks of the spoon. Ever since I had the children, it's as if I am always watching something from the corner of my eye, just out of sighta peripheral haunting.

A couple of years ago, cheap synthetic drugs became more prominent on the island; now I imagine Shabu men lurking in the shadows-breaking windows-stealing anything they can smoke or sell. You can see it in their eyes when you pass them in the street, that glaring methamphetamine desire. Almost pretty, the glint, like the sharp edge of a shard of glass. Slkt, they could cut you for the slightest gain. How the blood would flow like lava.

Sometimes I imagine them smashing into the house when I'm alone with the children, and I'm frozen in a frenetic terror that lasts until the next day.

The foyer opens out to a large dining room framed on either side by a marble staircase. I walk towards the bar to refill my wine. 
'Do you think she knew that Oscar and Emma ...?' two wives of local bar owners talk in a hush in the line as I approach.

'Oh! Vera! Hi!' the British one, too loud.

Mwah, mwah I kiss their cheeks with the lightness of the petals that float in the water bowls on each dry bar. I know what they're talking about. It's not the first time I've been the subject of island gossip; when there are no papers or tabloid magazines, women are bound to make their own news.

Of course I knew, I think to myself, as the bartender refills my glass. Oscar had affairs with just about every girl on the island that stuck around for more than a month. Emma was no different. Sometimes he told me if I asked. Sometimes I didn't ask. Sometimes, if I was in the mood, I joined in.

On this particular occasion, I happened to see them, in the linen room behind the bar. Through the slatted window half ajar, I saw the back of her, just another silly girl on her knees, and the front of him, head tilted back, hands pressed gently against her skull as if he might, at any moment, apply pressure and pop her open like an egg. I still remember the sound-glug, glug-like yolks slopping into a bowl.

I didn't say anything, just picked up the new case of wine propped against the wall, and returned to the party. What was the use? We'd be going home soon anyway, and things would be different.

I make my way back outside and do the rounds; the familiarity of faces is as bland as the food from the local market. The same parties, the same people, the same complaints. I play a game with myself and try to discern who knows about the body on the beach and who doesn't by the particular flicker in each set of eyes.

I imagine code words; camembert means the corpse of a mangirl. A dead body probably laid out by now in the hospital in Dapa, waiting for the real police to arrive on tomorrow's ferry, waiting to be prodded and examined and mined. I think of those lifeless eyes. Azure blue, serene as the swimming pool, sparkling like the sound of spilt marbles. 
The bar's closed on Sunday, so Eddie asks me if I want to go with him to the cockfights. He has a prize bird fighting tonight. I want to say no but I never went last time. Some girls I surfed with said it was so horrible they cried. Curiosity gets the better of me though, so I agree and climb onto the back of his bike, nursing the virulent bird on my lap.

'Hold the wings,' Eddie says as he kicks the engine over.

My fingers press down, bones jutting up against my palms, testing the restraints. Little beady black eyes looking right into mine. I remember my first horse, lame with age, that look of desperation and resignation as Dad got his gun. I wonder if that's what Emma's eyes would've been like if I made myself look at them.

'Sorry mate,' I whisper to the feathered head.

Tucked behind the sports equipment store, off a dirt road near the Jungle Disco, the parking lot overflows with motorbikes. Immediately I'm aware of my body--colour, shape, sex. Walking towards the front entrance with Eddie, the crowd is mostly male. I spot one other female tourist; otherwise the local women in attendance are aged and rough, faces twisted into snarls, clenching fistfuls of bills and surveying the competing birds lined up for inspection outside the ticketing area. Next to them I look feminine as a Barbie doll.

The building is an oversized shed like the one where Dad kept his tractor on the farm, the interior concealed by a barrier of wooden stakes that towers three metres up. We slip through the narrow entrance, Eddie thrusting two twenty-peso bills into the crusty hands of the man handing out tickets. I step over the globs of spit in the dirt-an orange haze getting kicked up by feet rushing to claim a seat in the grand stands. Guys buy beer and cigarettes from vendors on the other side of the fence. Eddie grabs us two cans as we pass, hot as piss.

The smell inside makes me dizzy-bird shit and blood soaked into the dirt. The steps of the grandstands are cracked in parts, some planks of wood missing, the whole thing swaying like it might come down any minute. Eddie shows me how to bet, scrunching up small bills and hurling them at bookmakers who must have impossibly good memories. I watch the crowd chucking their paper balls, prayers for birds who hold tomorrow's fortune in their clawed feet.

Getting into the spirit, I put a bet on Eddie's fluffed up mound that warmed my lap on the way over. We cheer as the cock is dropped into the ring. Much bigger than its opponent, chest out and firm, the long razor sharp barb attached to its foot catches the fluorescent light that hangs and sways. Rushing, the birds make easy cuts into each other, the two-inch spikes disappearing all the way in. Feathers fly and float down. Blood stains and clumps the dirt-I remember the sand beneath her body. Emma Kent. Emma Kent. Emma Kent. I look away.

Surveying the room my eyes settle on a group of male foreigners, drunk and rowdy. When the crowd erupts into a roar, they jump to their feet, pound their fists into the air. A longhaired, Fabio type catches my eye and winks. Grimacing, I roll my eyes and watch Eddie's face 
transfixed on the ring. Suddenly, the sound stops like someone has pressed pause on the scene, and I know the fight is over. The men cheer and high five. Eddie scrunches his ticket up, throws it below the stands and walks out without a word.

Back in my room I look at the flyer for Emma's memorial that Mary printed. In pixelated black and white, she's still a stunner. Big round eyes, a Botox pout, blouse scooping down to just above her belly button. I sift through the scraps of paper, wanting to know something, anything, about her. I trace a finger over her hand writing: tight, even, restrained characters.

On a piece of blue card there's a list of place names and dates like a makeshift travel journal. Some little square post-it notes scribbled with quotes: Audre Lorde, Kathleen Hannah, Sylvia Plath. I shuffle until I see a lined page ripped from a pad. Laid out in stanzas, the words drift apart like they were scrawled with passion. I'm no poet, but I'm transfixed by this snippet of her interior world. One verse jumps out, and I read it over and over, wondering who this mystery man is, until my eyes are foggy for sleep.

Fingers interlace

like a zebras stripes, or spilled ink

on a white page.

A love letter

licked with a pink tongue, hidden and

devoured in secret over and over.

Inside your tiny room, our limbs were

a menagerie, but you were the only one who,

never wanted to tame me. 
Monday 
The boat engine cuts - I toss my board over the edge and paddle away from two tanned men jostling for a wave.

I move into the rotation over on the left where there are fewer bodies, the large walls of water break overhead and roll long and smooth along the surface of the reef. Turning my nose to the mountains in the west, I kick my legs and feel the force beneath me as I spring to my feet and ride into a green grass tunnel.

I am in a timeless garden.

I am back on the farm with Dad, kicking a footy behind the house.

I am not here.

Popping out the other side, everything is as it was before, but the calm feeling lasts like the burn of salt on my lips.

Returning to work, I park my bike by the stables. Down the path towards the bar I hear a weird noise that I can't quite pick. Squealing. The children fighting? I carry my board down to the racks to check it out. On the lawn Eddie stands holding a small pig by its throat in a headlock.

'Oh good,' he says, 'you can help me.'

'With what?' I ask.

'The lechon,' he says, 'for the memorial!'

I remember from my last visit: lechon is the signature dish at any Filipino special occasion. A whole pig roasted on the spit, sourced locally, the younger the better for a more supple taste. I screw my face up and shake my head. We grew apples on the farm. No slaughtering in my childhood.

'Just hold it!' he says waving a scythe in the other hand.

I put my board down and walk over, place my hands gently on the animal's fuzzy neck. Grunting, it twists and I grip harder, the soft pink skin of its nose pressing against my bare leg.

'I ca...' I start but before I can finish it's done. Eddie's hand slices in a swift motion and the baby pig's throat splits open like a water balloon. Blood sprays over our feet. He grabs the rope he's pre-tied around the animal's back feet and swings it over a railing behind the storeroom, stringing it up so the blood drains into a large metal tray.

'We will use the blood for sausage,' he says. 
I blink in disbelief, look down at my hands; the colour of sap, or the nail varnish that airhostesses wear. Her body. Emma Kent.

'You can wash,' Eddie says oblivious, 'then meet me back here so we can start setting up.'

When the sky starts to dim, Eddie and Joshua position kerosene lamps around the garden edge and pile sticks ready to light. Mary lays out the table with a selection of salads and fruits to go with the lechon. She peels the husks of palms apart like sheets of paper from a sheath, sturdy makeshift plates: island style. Soon the lawn in front of the bar will fill with those who knew Emma and a bunch of backpackers cashing in on the free feed.

When people arrive there are teary recollections, but before long Tanduay flows, and the night turns into the usual wild affair. I walk out to the ledge by the beach and sit, looking up at the Milky Way's pinks, oranges, and purples, wounding the night sky like a magnificent bruise. I remember Emma's body, bruised like the Milky Way. I want more for her than this bogus send off; I don't know what exactly, but I want it so bad it hurts.

Down on the beach, embers rise in the smoke as if trying to reach the galaxy overhead. Around the edge, a crowd gathers as a tourist from Scotland sits down with his acoustic guitar. Strummed sounds bounce off the water with the familiar chorus of warm beach nights. His fingers pluck a well-known melody, an almost eye-rolling song in every drifter's songbook.

'Some day, I wish upon a star, and wake up where the clouds are far behind me,' his voice drips.

Bedraggled-haired girls with sun-kissed noses rest their heads together and sway. I wonder which star she wished on? Whether those who did it to her are here, sitting around the bonfire or up on the lawn guzzling beer?

I stare into the depth of the fire, to the place where it's blue, and watch the edges of her turn up and dissolve to ash. 
The children are inside with Mary, who checks for their breath like I taught her. I soak up the energy. I've always loved parties. Jill sits and watches the fire cut through the darkness, her face lit up. The embers pop, pop and crackle. Her pale skin has already taken some sun and is changing like autumn leaves--the exuberant foliage of youth falling off her bones. Funny how ugly things bring out the best in women, like when Grace lost all that weight after her divorce.

My eyes brush over the faces of revelers, looking for them. First I spot the French guy standing by the table of food, leaning over a girl in a garish floral dress, breathing his beer soaked accent all down the front of her. Then I see the other one, the German, sitting on the steps of one of the bungalows looking off at nothing in particular. The simple gesture of running his hand through his hair takes on so many words. Fear, regret, shame...

On the morning I saw Emma and those boys on the beach, l'd sat in the chair by the children's bed all-night, unable to sleep. Some days I feel like every thought l've ever had is in my head at once. I imagine that if I blink the Shabu men will break the glass, smash my skull open, and take them all from me. They will huddle around in a sickening pack and turn my memories to smoke in their foil tubes.

I'd walked out on to the beach to escape the drowsiness between waking and sleep that hangs like the mobile over Ivar's cot, hypnotising me, floating figures and lilting lullabies.

I heard them then, laughing. I saw them, on top of her, one and then the other. I was frozen still. I watched as she groaned, from pleasure, pain? I couldn't be sure.

Now, the two of them are on my lawn, and she is lying in a box ready for the hull of a plane. The guilt those poor boys must feel.

I walk over to the German sitting alone and offer him a beer; make small talk about the winters at home.

Down the driveway, I see Officer Cruz arrive in the rusted police van. Sputter, sputter, clunk. He turns off the engine and climbs the small ladder to Joshua's room, knocks on the thin wood, climbs back down and waits. The horses stir in their stables, blowing air out through their noses in guarded sighs.

Joshua climbs down the ladder and talks with large gestures. I can't hear over the music but I can see he's shouting. Cruz's hand reaches for Joshua's arm, but he pushes it away. I knew he was coming, of course. What else do we pay for? l've already arranged for the replacement to arrive from Cagayan on the first boat tomorrow. No shortage of poor farm boys willing to relocate to paradise. I wish it could be someone else, but everyone knows about him and Emma, it makes the most sense. 
The French and the German tourists exchange the slightest furtive glance, before the German returns to our conversation.

'In a few days I'll be back home,' I say, 'How I look forward to being cold.'

'Me too,' the German says. 'I leave on Friday.'

I see it, the weight lifting from him, his face lightening with thoughts of tomorrow and the next day and his whole future, returning. The image of her hybrid body no longer occupying every crevice of his mind-whirrrr, whirrrr, unpleasant drunken snapshots pushed out his ears like forgotten polaroids. He knows Emma was alive when he walked away, or at least, he thinks so. The rest will be a mystery he will carry always.

'Another beer?' I ask.

He nods, a handsome smile, his straight teeth like the polished headstones of the wealthy, in the cemetery just down the beach. 
No bloody way! I rush up from the beach to where Cruz pushes Joshua's head into the back of the van, but I'm too late. He shakes his head at me, won't listen as he gets in the driver seat and pulls away.

The party goes on as if nothing has happened, but I have no stomach for it. I go to my room, wonder if it could've been him, read the poem, put the pieces together. I imagine their fingers locked together, the little triangle window fogged with their breath.

'Maam Jill,' Mary whispers through my door.

I open it and see her there, Eddie hovering behind.

'We are going to my village, to say our own goodbye to Emma, if you want to come...'

'Um, yeah, alright,' I nod, realising that not a single island local was at the memorial, the white washed scene resembling a uni house party, and I suddenly feel sick about the whole thing. It wasn't Joshua. Of course it wasn't; it was probably some slick traveler already long gone to Indo or Vietnam.

Mary's village is tucked into the hills down a maze of rocky paths that cut in from Tourism Road. My hands wrap tight around Eddie's waist as the bike bumps and jumps its way along. I lean my head in the centre of his back and close my eyes so that it feels like a ride at an amusement park.

The small houses circle around an open space set up with trestle tables, fragrant with traditional dishes: adobo, tapa, merchado. An old woman with long gray hair thrusts a plate toward me. No lechon here; the cuts of meat are sinewy and fatty.

From the loud, rum-soaked shouts of the men, it's clear the party is already in full swing. Mary introduces me to her family and friends, each grabbing my hands, offering me food, drink, a chair to sit. Within minutes my arms are full, and I look awkwardly for a place to set something down. I couldn't possibly eat, but l'd love a long swig from one of those bottles being passed around.

'Did Emma come here?' I ask Mary.

'Yes Maam,' she replies, 'She came to the fiestas, she loved to dance.'

I imagine her twisting and turning to the Filipino pop songs playing loudly. A man about the age Dad'd be now, wreaking of booze, grabs my hand and pulls me onto the makeshift dance floor. I laugh as he pirouettes me.

Early hours of the morning, Mary, Eddie and I sit in a drunken quiet. 
'Were they in love?' I ask.

'You mean Emma and Joshua?' Mary replies.

'Yeah,' I nod. 'Did he know...?'

'He knew everything about her...,' Mary says, 'He loved her how she was.'

'Why do you reckon they arrested him then?' I ask.

'It's just the way it is here,' she sighs, 'when my sister died last year, raped and killed, the police didn't do anything, but when it's a white girl...'

'Someone has to suffer so they can all keep making money,' Eddie spits.

'That's shit,' I reply, instantly aware of how much of an understatement that is.

Mary and Eddie don't say anything, and I realise corruption is a reality they've given up coming to terms with.

Eddie reaches over and takes my hand, his thin dark fingers intertwining with mine. Wind picks up promising good surf tomorrow; the island exhales a long breath. 


\section{Coda}

Body laid out on a metal table. Not a shred of cloth covering the greying skin. Muscular arms rest beside the faintest curvature of hips, a slender stomach. Small coarse hairs sprouting from areolas, quivering slightly in the air conditioning.

Nurses in white uniforms toss sheets to the air, flapping like gulls in flight. Carefully, they wrap the large feet with sparkling nails, then the long smooth legs. Hovering over the abdomen, one of the nurses pauses. She takes the firm but still malleable penis in her hand, small enough to wrap in her fingers, and presses it down between the thighs. The shock of trimmed pubic hair covers the burrow, and she nods before continuing the binding.

Slight wiry men in navy coveralls come with a pine box on a trolley and struggle as they lift the heavy weight inside. In the sterile room the chemical smell is sweet at the edges - a hint of decay cuts through. Sliding and grunting, the box is arranged in the back of the van for the short drive to the airport.

The tired driver accelerates through the countless potholes while the cargo bangs into the walls barely audible over the blaring American pop. He drives right up to the hull of the plane, opened to receive its final passenger. The ground staff secure the container in the hold as the propellers sputter to life. 


\section{Research Statement}

\section{Research Background}

$\mathrm{T}$ he dead girl is a trope that permeates culture in powerful and often insidious ways; not only found in the pages of the crime genre, she seeps across mediums and into reality. This short story "Island" was born from questions surrounding the frequent employment of the dead girl trope, such as: what does the dead girl mean on a macro level? Why is the sexualised representation of a girl's discarded body so titillating? What happens when the dead body doesn't meet dominant expectations? And how can fiction work as a means to reconfigure our imaginations?

\section{Research Contribution}

Inspired by corporeal feminism, corporeal writing and crime writing that defies classification, 'Island' seeks to push the boundaries of representation, and subvert the more misogynist aspects of the crime genre, such as the sexualisation of the dead female body, and the oftpresent underlying message that women who don't conform to societal moral expectations will be punished. The work crosses the threshold between popular genre and literary fiction, utilising genre specific signposts to draw in readers before subverting expectations, demonstrating how the dead girl can be reconstructed to disrupt prevalent notions of the body.

\section{Research Significance}

The bodily experiences of, and violence committed towards, trans people, women and people of colour are still largely under-represented in crime fiction. "Island" functions as both a critique of the crime genre as well as an exercise in blurring binaries and singular corporeal subjectivity. Intentionally shying away from traditional resolution, "Island" mirrors the still unresolved issues of representation across our culture and prompts further thought and investigation into unquestioned tropes and assumptions. 